\title{
A Response to Dion, Sumner, and Mitchell
}

\author{
Maya Sen
}

Associate Professor, Harvard Kennedy School, Cambridge, MA 02138, USA.Email: maya_sen@hks.harvard.edu, URL: http://scholar.harvard.edu/msen

The findings of Dion, Sumner, and Mitchell (2018) are striking: female political scientists are cited less frequently than are male political scientists, particularly when men are doing the citing. In addition, these patterns persist, although the gap is lessened, in fields where scholarship by women is more prevalent (such as gender and politics). All of this is troubling: citations are important not just for career outcomes but, more broadly, for determining which scholarship becomes field defining. Put simply, the findings in Dion, Sumner, and Mitchell (2018) imply that female scholars are at a long-term disadvantage in staking out their contributions to knowledge, and the study of politics is worse off for it.

How can the discipline respond? First, a key finding of Dion, Sumner, and Mitchell (2018) is that "more gender diverse subfields and disciplines produce smaller gender citation gaps." This is an important starting point: although we cannot randomly assign women to subfields, we can certainly promote programs and interventions to encourage more women to both remain in political science and to consider and stay in subfields where they are less well represented. ${ }^{1}$ There are no easy shortcuts here. The onus is on departments, advisors, search committees, and individual scholars to address these imbalances at a fundamental level, making these subfields more welcoming to women. This includes investments not just at the graduate-school level, but as part of faculty hiring and retention and in the promotion of women in discipline-wide positions of leadership. Implicit in Dion, Sumner, and Mitchell (2018)'s argument is that women cannot be cited if they are not producing research in certain areas; not giving women the opportunity to succeed can only worsen the citation gap.

This general "numbers" issue, however, does not address what individual authors and journal editors can do now to help combat the gender citation gap. Here, I consider three possible "blind spots." All of these represent possibilities for the profession to explore, using our discipline's tools of data analysis and experimentation. These blind spots also plague all of us, giving individual scholars a key opportunity for self-reflection and action.

The first "blind spot" involves the important moment when authors begin to explore the state of the literature. In terms of building a literature review, most authors tend to "go where they know," starting with papers listed in graduate-school syllabi. However, as scholars have shown (e.g., Colgan 2017), syllabi themselves often suffer from lack of diversity. ${ }^{2}$ Individual faculty can nonetheless work to diversify syllabi. Jane Lawrence Sumner, for example, has developed an easy-to-use tool for checking the diversity of syllabi, ${ }^{3}$ and chairs and department heads can encourage its use more widely. Research also suggests that having a female professor can increase

Political Analysis (2018) vol. 26:335-337

DOI: $10.1017 /$ pan.2018.15

Corresponding author Maya Sen

Edited by Jeff Gill

(C) The Author(s) 2018. Published by Cambridge University Press on behalf of the Society for Political Methodology.
Author's note: Thanks to Michelle Dion, Jane Lawrence Sumner, Sara Mitchell, and Jeff Gill for inviting me to respond to this paper and to Dara Kay Cohen and Melissa Kappotis for helpful feedback.

1 According to the American Political Science Association, women make up 18\% of political methodologists, 31\% of political theorists, and $35 \%$ of Americanists and those in international relations. The numbers are more equitable in comparative politics (42\%) and in public policy (41\%). See http://www.apsanet.org/RESOURCES/Data-on-theProfession/Dashboard/Membership.

2 Many graduate syllabi focus on "the canon," which may itself be lacking in diversity. Opportunities nonetheless remain to enrich the canon with recommended readings, which could bring in more recent scholarship, or to juxtapose the "classics" with newer interpretations.

3 https://jlsumner.shinyapps.io/syllabustool. 
the diversity of topics covered (Hurtado 2001); in this spirit, departments can consider having more female faculty teach introductory or field seminars. Ultimately, diversifying the works with which early-stage scholars engage is a small, albeit small step in evening out gender gaps.

The second "blind spot" is that authors tend to go "to whom they know" to figure out what people are working on. In trying to figure out contributions to the literature, we all ask ourselves, "What was the last paper I saw on topic X?" or "Who do I know who works in field Y?" Many scholars look no further than the last conference they attended, the last related tweet they saw, or the latest speaker in their department's seminar series. However, research from across academia tells us that men are more likely than women to benefit from networking (Gersick, Dutton, and Bartunek 2000), to self-promote (e.g., Moss-Racusin and Rudman 2010), and to do invited talks (Nittrouer 2015; Schroeder et al. 2013). These patterns could further sustain the gender citation gap. Fortunately, we have excellent tools to "check" against these biases in social media promotion or invited speakers' lists. The increasingly comprehensive, easy-to-search list at Women Also Know Stuff provides information on nearly 1,500 female scholars by subfield (Beaulieu et al. 2017). ${ }^{4}$ Department chairs and disciplinary leaders should also consider having equitable shares of women and men organize seminars or speakers' series (including doing the all-important inviting and attendant networking) and serve as conference organizers or section leaders; research shows that having women in this capacity may increase the amount of female-authored scholarship presented (Sardelis and Drew 2016). And all social media users can do more to promote female-authored scholarship via Twitter and Facebook.

A third "blind spot" is simple unthinkingness-hardly an excuse, but something of which we are all guilty. When facing a revision deadline or a strict word count, what scholar has not cut a citation or two in a haphazard-and probably implicitly biased-way? On this point, the behavioral literature suggests that small interventions can "nudge" people in constructive ways. For example, journals routinely conduct technical checks on manuscripts; these oftentimes flag issues with a submission's citations-for example, if the authors have cited an unpublished paper. A straightforward intervention could be for editors to provide authors with a technical check that automatically scans for citation diversity. This could include informing the authors of (for example) the total number of citations, modal journals and authors cited, and gender breakdown of authors cited. Such an intervention would not be cumbersome, but, by giving authors the chance to revise papers in light of such a report, editors could play a part in "nudging" authors toward increased diversity in works cited.

In light of Dion, Sumner, and Mitchell (2018)'s robust findings, these ideas are unlikely to engender widespread changes, at least not in the short term and not without meaningful increases in female representation through academic ranks and subfields. Thus, my last suggestion is to provide tenure and promotion committees-many of which explicitly rely on citation statisticsinformation on the gender citation gap, particularly in fields where there are few women and thus, according to Dion, Sumner, and Mitchell (2018), the gap might be wider. There is a useful analogy here to student course evaluations, which have been shown to be biased against female instructors (Mitchell and Martin 2018). Across many universities, research on biases in student evaluations is provided to administrative committees; the same can be done with information on the gender citation gap, starting with Dion, Sumner, and Mitchell (2018)'s own research.

These issues are complicated; the burden falls to the entire discipline to work collectively in addressing these inequities. I am grateful to Dion, Sumner, and Mitchell for doing some of the research necessary to bring attention to these issues and encourage other scholars to engage in similar inquiries. What we do with information such as this will define us as disciplinary leaders and lay the foundations for more diverse and impactful scholarship in the decades to come.

4 https://womenalsoknowstuff.com. 


\section{References}

Beaulieu, Emily, Amber E. Boydstun, and Nadia E. Brown et al. 2017. Women also know stuff: Meta-level mentoring to battle gender bias in political science. PS: Political Science \& Politics 50(3):779-783.

Colgan, Jeff. 2017. Gender bias in international relations graduate education? New evidence from syllabi. PS: Political Science \& Politics 50(2):456-460.

Dion, Michelle L., Jane Lawrence Sumner, and Sara McLaughlin Mitchell. 2018. Gendered citation patterns across political science and social science methodology fields. Political Analysis 26(3):312-327.

Gersick, Connie J. G., Jane E. Dutton, and Jean M. Bartunek. 2000. Learning from academia: The importance of relationships in professional life. Academy of Management Journal 43(6):1026-1044.

Hurtado, Sylvia. 2001. Linking diversity and educational purpose: How diversity affects the classroom environment and student development. In Diversity challenged: Evidence on the impact of affirmative action, ed. Gary Orfield. Harvard Education Publishing Group.

Mitchell, Kristina M. W., and Jonathan Martin. 2018. Gender bias in student evaluations. PS: Political Science \& Politics 1-5.

Moss-Racusin, Corinne A., and Laurie A. Rudman. 2010. Disruptions in women's self-promotion: The backlash avoidance model. Psychology of Women Quarterly 34(2):186-202.

Nittrouer, Christine Lynn. 2015 Lacking a voice: Bias against women as academic speakers at top universities. Master's thesis, TX: Rice University Houston.

Sardelis, Stephanie, and Joshua A. Drew. 2016. Not 'pulling up the ladder': Women who organize conference symposia provide greater opportunities for women to speak at conservation conferences. PLOS ONE 11:1-20.

Schroeder, Julia, Hannah L. Dugdale, and Reinder Radersma et al. 2013. Fewer invited talks by women in evolutionary biology symposia. Journal of Evolutionary Biology 26(9):2063-2069. 